\title{
Editorial
}

\section{Difusión del uso del ORCID}

La Universidad Surcolombiana desde su misión y visión plantea la formación de profesionales e investigadores, en este sentido, considera que es importante divulgar los productos de la investigación a través de los diversos canales (libros, artículos, participación en eventos, entre otros) y de esta manera posicionar la producción científica que se realiza.

En este sentido, la Revista Ingeniería y Región a través de su proceso editorial promueve de manera conjunta con los autores y evaluadores, la importancia del registro de la información (formación académica, filiación, intereses temáticos y el uso del identificador ORCID, entre otros); para asegurar el reconocimiento de las contribuciones realizadas por cada uno de ellos y conservar dicha información con el paso del tiempo.

Con base en lo anterior, el Open Research and Contributor ID (ORCID) invita a que el mundo participe de la investigación, la erudición e innovación donde los investigadores están identificados de forma única, y "conectados a sus contribuciones a través de disciplinas, fronteras y el tiempo" (ORCID, 2020). También proporciona a los autores un código único que se distingue y diferencia su producción científica, para evitar confusiones vinculadas a la autoría y existencia de nombres personales coincidentes o similares, pues el ORCID de un investigador será siempre el mismo, sobrepasando las barreras lingüísticas, de filiación institucional o las vinculadas a la normalización de firma científica (Biblioteca Universitaria Huelva, 2020). En este sentido, la Revista ha facilitado un tutorial en el OJS (Open Journal System) (https://journalusco.edu.co/index.php/iregion/tutoriales) para orientar a aquellos que aún no lo tengan.

La iniciativa del ORCID surgió en el 2009, con la finalidad de conectar investigaciones e investigadores (disponible en el siguiente enlace https://orcid.org/), de esta manera cada investigador podrá registrarse para obtener un único identificador digital, adicionar la información profesional, experiencia, proyectos y finalmente, compartirlo en su firma digital, Curriculum vitae (Hoja de vida), páginas web, publicaciones; ya que esta información es solicitada por parte de las revistas científicas a los autores y revisores.

Esta herramienta es de gran importancia en tanto son muchos los trabajos realizados en las Instituciones de Educación Superior que no son publicados. En la Facultad de Ingeniería de la Universidad Surcolombiana se generan cerca de 80 trabajos al año, menos del 10\% son publicados en Ingeniería y Región o en revistas externas de carácter nacional o internacional. En este proceso, es clave la orientación del director del proyecto para mostrar a sus estudiantes que es posible graduarse y presentar en su hoja de vida una publicación. Ciertamente, este proceso toma tiempo, requiere del análisis, selección de la revista apropiada, pero es un esfuerzo que vale la pena realizar y de esta manera mostrar el trabajo que se realiza desde la Universidad Pública en la región del sur de Colombia.

Claudia Milena Amorocho Cruz https://orcid.org/0000-0003-3986-5768

Editor

PhD. Biotecnología

\section{Referencias}

ORCID, 2020. https://orcid.org/blog/2020/06/09/black-lives-matter-orcid\%E2\%80\%99s-response

Biblioteca Universitaria Huelva, 2020. https:/guiasbuh.uhu.es/ORCID 